\title{
Análise do comportamento de estruturas de concreto com fibra de polipropileno sob flexão
}

\author{
Behavior analysis of flexural concrete structures with polypropylene fiber \\ Viviane Alves Silva*, Reinaldo Ferreira da Costa Júnior, Ana Carolina da Silva Lima Vianna, Nirvana \\ Bartko, Adauri Silveira Rodrigues Júnior, Gustavo José da Costa Gomes
}

Como citar esse artigo. Silva,VA; Costa

Júnior, RF; Vianna, ACSL; Bartko, N; Rodrigues Júnior, AS; Gomes, GJC. Análise do comportamento de estruturas de concreto com fibra de polipropileno sob flexão. Revista Teccen. 2019 Jul/Dez; 12 (2): 23-29.

\begin{abstract}
Resumo
O concreto possui uma série de qualidades, tais como excelência à resistência à água (comparado com outros materiais estruturais), facilidade na execução, devido ao seu estado fluido, permitindo variabilidade de formas e tamanhos, disponibilidade e baixo custo dos ingredientes, o que the garante um local de destaque sendo o material estrutural mais empregado no mundo. Entretanto, o concreto ainda apresenta certas limitações, como por exemplo, o comportamento frágil nas estruturas e uma capacidade minimizada de deformação, em regime plástico. O concreto apresenta ainda uma baixa resistência à tração quando igualado a sua resistência à compressão. Concordante à sua susceptibilidade a solicitações de flexão, aparecem no concreto fissuras e as microfissuras na região tracionada. Umas das soluções técnicas possíveis para minimizar essas limitações é o uso de fibra como reforço no concreto, que lhe garante comportamento dúctil frente aos esforços solicitantes. O presente estudo tem por objetivo analisar os resultados obtidos através do ensaio de flexão de três pontos de corpos de prova prismáticos elaborados com concreto simples e outros com concreto incorporado com fibra de polipropileno. Para realizar a análise foram utilizados traços de $40 \mathrm{MPa}$ e $20 \mathrm{MPa}$ de fck. Concluiu-se que aadição de fibra de polipropileno em uma matriz cimentícia, mesmo com um corpo de prova com um fck inferior, diminui a fragilidade que o corpo tem após o tempo de cura.Assim, mostra que tão importante quanto o fator de compressão do concreto, é o seu comportamento à ductilidade, o que lhe confere maior resistência à tração, uma vez que os elementos estruturais sempre estão submetidos a ações combinadas de esforços.

Palavras-Chave: concreto, fibra de polipropileno, flexão.
\end{abstract}

\begin{abstract}
Concrete has a number of qualities such as excellence in water resistance (compared to other structural materials), ease of execution due to its fluid state, allowing for variability of shapes and sizes, availability and low cost of ingredients, which guarantees it a prominent place being the most used structural material in the world. However, concrete still has certain limitations, such as the fragile behavior in the structures and a minimized deformation capacity in plastic regime. Concrete also has a low tensile strength when compared to its compressive strength. According to its susceptibility to flexural stresses, cracks and micro-cracks appear in the tensioned region. One of the possible technical solutions to minimize these limitations is the use of fiber as reinforcement in the concrete, which guarantees its ductile behavior against the requesting efforts. The present study aims to analyze the results obtained through the three-point flexural test of prismatic specimens made with simple concrete and others with concrete incorporated with polypropylene fiber. To perform the analysis, $40 \mathrm{MPa}$ and $20 \mathrm{MPa}$ FCK traces were used. The work concludes that the addition of polypropylene fiber in a cementitious matrix, even with a lower FCK specimen, decreases the fragility that the body has after curing time. Therefore, it shows that, as important as the concrete compression factor, is its ductility deportment, which gives it greater tensile strength, since the structural elements are always subjected to combined efforts.

Keywords: concrete, polypropylene fiber, flexing.
\end{abstract}

\section{Introdução}

Ouso de materiais compósitos no setor construtivo é antigo. Alguns autores remontam ao desenvolvimento da prática aproximadamente ao período em que surgiu a técnica de fiação (Ventura, 2009). Na engenharia civil, é de mais fácil identificação um dos grandes avanços tecnológicos pelo uso de compósitos: o concreto reforçado com barras de aço surgiu na segunda metade do século XIX (Denardi, 2016).

O concreto, então, era e continua sendo o material mais utilizado na construção civil. Denardi (2016) menciona que seu uso anual é estimado em mais de 11 bilhões de toneladas métricas por ano. O uso do material se justifica por diferentes fatores, desde o seu custo até adequabilidade de suas formas e tamanhos. Contudo, o concreto não reforçado apresenta determinadas características desvantajosas. Dentre elas, destaca-se a baixa relação entre resistência/peso (Figueiredo, 2011).

A solução de concreto armado desenvolvida no século XIX orientou uma solução para esse problema. O reforço com barras de aço ampliou consideravelmente

Afiliação dos autores: Afiliação dos Autores: ${ }^{1}$ Universidade de Vassouras - UV, Vassouras, RJ, Brasil. 
a relação resistência/peso do concreto. Os avanços, contudo, não foram absolutos e promoveram desvantagens antigas e novas na área das construções.

Como salienta Denardi (2016), uma das grandes desvantagens de tal compósito está na vulnerabilidade do aço à corrosão, que pode gerar novas patologias na estrutura e mesmo diminuir a sua durabilidade. Além disso, a prática de criação do compósito demanda um pátio específico de montagem das armaduras, consumindo considerável tempo e espaço.

O uso de fibras no concreto tem se destacado neste século como um dos grandes avanços da Engenharia Civil, eliminando as desvantagens acima mencionadas. Ainda incipiente no Brasil, a pesquisa sobre o concreto reforçado com fibras (CRF) tem sido amplamente realizada nos países desenvolvidos, especialmente nos Estados Unidos e na Europa (Figueiredo, 2011).

Visando uma contribuição nessa temática, este trabalho propôs um ensaio de tração indireta, verificando empiricamente a resistência de diferentes corpos de prova com variadas composições, analisando, especialmente, o comportamento dos corpos mediante a adição de fibras de polipropileno.

\section{Concreto}

O concreto é um material originário do composto de: aglomerantes, agregados e água, em proporções adequadas. Atualmente, o concreto possui uma série de qualidades que lhe garante um local de destaque sendo o material para fim estrutural mais utilizado no mundo. Entretanto, o concreto ainda apresenta uma série de limitações, como por exemplo, o seu comportamento frágil nas estruturas e uma capacidade minimizada de deformação, antes da ruptura, quando submetido à tração. $\mathrm{O}$ concreto apresenta ainda uma baixa resistência à tração quando comparado a sua resistência à compressão. Propício a sua susceptibilidade à esforços de tração, aparecem no concreto algumas fissuras e as microfissuras que podem aparecer no seu interior. Segundo Neville (2015), a resistência do concreto normalmente é considerada sua propriedade mais importante. Umas das soluções técnicas possíveis para diminuir essas limitações é o uso de fibra de polipropileno como reforço no concreto.

\section{Fibras na matriz cimentícia}

Um material compósito é composto em duas classes: a matriz e o reforço. A matriz é responsável por dar a forma estrutural do material e o reforço confere à matriz o aumento ou o surgimento de propriedades.

O concreto possui características que são decorrentes dos materiais que são empregados em sua matriz, que geralmente é composta por cimento e água, podendo ainda conter agregados graúdos e miúdos em sua mistura que lhe dão origema argamassa ou a pasta. A partir dessa mistura, é originado um material de estrutura frágil, com baixa resistência à tração e que sofre com o aparecimento de fissuras mesmo no processo de cura.

Silva (2006) explica que devido à atuação de carregamentos, ocorrem deformações que geram tensões internas em sua matriz e quando superiores ao seu nível de tensão de ruptura, originam pequenas fissuram que podem ser agravadas e ampliadas devido a essa concentração de tensão.

Mehta e Monteiro (2008) enfatizam que mesmo antes das tensões externas atingirem a estrutura, há microfissuras presentes na zona de transição entre os agregados e a matriz que aumentam ainda mais a propagação das fissuras.

Em um material incorporado com fibras, a fratura da peça é retardada, tornando o material quase dúctil se comparado ao mesmo sem a adição das fibras, que sofre uma ruptura brusca. Isso se deve ao fato de as fibras trabalharem como uma ponte de transferência das tensões que originam as fissuras, o que diminui a concentração destas nas extremidades das fissuras, tornando resolutivo qualificar o comportamento do material compósito como pseudo-dúctil ou frágil, frente às aplicações de tensões. (Figueiredo, 2011).

As fibras devem ser capazes de suportar as cargas transferidas ao material e a presença delas são marcantes após o início da fissuração da matriz, onde observa-se que ocorre uma grande deformação sem que haja um rompimento de maneira brusca do material (Picanço, 2005).

Caratin (2014) frisa que o uso de elementos de reforço faz com que sua matriz adquira ductilidade, tenacidade, resistência ao impacto e à fadiga. A adição das fibras aos materiais de matriz cimentícias contribui ainda para o aumento da resistência à fissuração por retração e da sua durabilidade.

A utilização de fibras na matriz cimentícia influencia no desenvolvimento de fissuras na velocidade usual uma vez que estas agem como armadura tridimensional, redistribuindo as tensões, elevando a resistência do material pós-fissuração(Figueiredo, 2011).

A figura 1 esquematiza o comportamento das fibras sob a aplicação de tensões concentradas em uma fissura comparado com um elemento elaborado com as armaduras de aço convencionais.

\section{Fibra de Polipropileno}

O polipropileno é um material polimérico sintético derivado do propileno e possui uma massa específica baixa, a menor entre os termoplásticos, e 


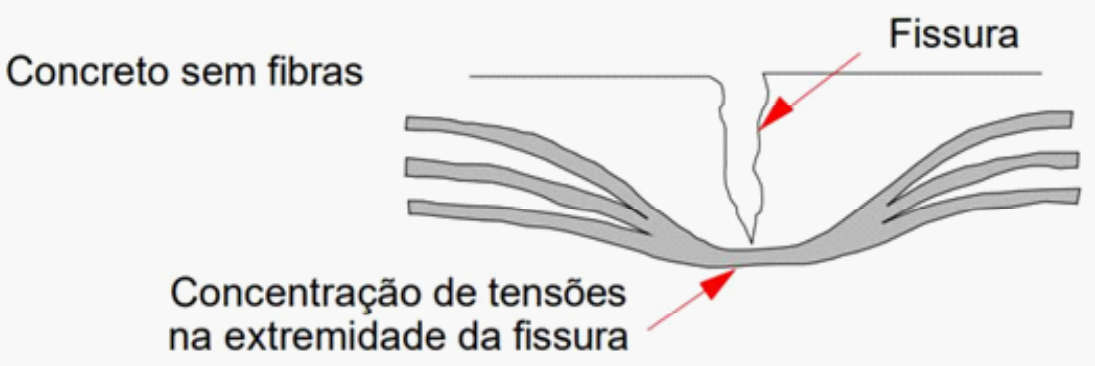

Concreto com fibras

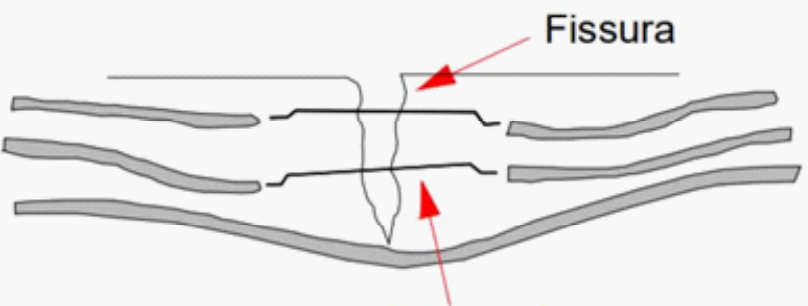

Fibras atuando como ponte de transferência de tensões

Figura 1. Atuação das fibras no compósito cimentício e redução do volume do elemento comparando a utilização de fibra e armadura convencional.

uma atraente resistência à corrosão (Isaia, 2007). Além disso, esse polímero possui uma alta versatilidade, sendo bastante usado para fabricação de recipientes plásticos, estofados e até roupas, sendo acima de tudo um produto reciclável. Por possuir um baixo peso específico, todo produto em que ele é empregado se torna leve e com baixo custo.

A fibra obtida através desse material é bastante usada como reforço para concretos e argamassas, sendo classificadas em duas formas distintas: macrofibras e microfibras, sendo esta última, apresentada em diferentes formas: monofilamentadas e fibriladas. No entanto, as monofilamentadas levam vantagem em relação às fibriladas por possuírem uma maior eficiência no combate das fissuras provenientes das tensões exercidas na matriz cimentícia, apesar de ambas possuírem mesma resistência e módulo de elasticidade (Bentur e Mindess, 2006).

Por não absorverem água, tais fibras levam vantagem se comparadas às fibras de aço, por exemplo, que estão sujeitas à corrosão e às fibras vegetais que sofrem degradação de microrganismos (Bentur e Mindess, 2006)

De acordo com Mehta e Monteiro (2008) as propriedades do concreto se modificam a medida em que se aumenta o teor de fibras no concreto. Enfatiza Jiang e Roy (1992) que ao se utilizar cerca de $2 \%$ do teor de fibra sobre o volume de concreto, ocorre não apenas uma diminuição na propagação dessas fissuras, mas também o desvio delas.

\section{Vigas Fletidas}

Em estudo recente, Borges (2016) afirma que os ensaios de tração direta seriam a forma ideal de caracterizar qualquer material à tração. $\mathrm{O}$ esforço único de tração uniaxial garantiria que os valores obtidos ao se aplicar a força não seriam sobrestimados.

Contudo, a metodologia possui características que dificultam a experiência com o concreto reforçado por fibras. Tomando como referência o formato dumbbel, um dos mais praticados na tração direta, o autor discorre sobre como a geometria do espécime, similar a um halter, poderia direcionar a orientação das fibras em porção específica da peça. A incerteza sobre a orientação das fibras dificultaria a análise apropriada do aumento da resistência adquirido com a introdução do elemento.

Nesse sentido, os ensaios de tração indireta aparentam aplicabilidade mais prática. É certo que, ao contrário do esperado no modelo de tração direta, a direção de aplicação do carregamento não será a mesma que a do esforço resultante. De fato, conforme Borges (2016), não há nesses ensaios um carregamento de tração propriamente dito, como no modelo anterior. Esse esforço é obtido através da disposição do apoio no objeto de teste, que tende a deformar sua estrutura.

Segundo o autor, é possível inclusive relacionar a história da criação do ensaio de flexão de placas à necessidade de mensurar a qualidade dos concretos projetados reforçados com fibras. Em síntese, buscava- 
se comparar as placas de concreto reforçado com tela de aço e as placas de concreto reforçado com fibra.

\section{Materiais e Métodos}

A metodologia utilizada para a realização do ensaio de flexão de três pontos foi a realização de 21 corpos de provas prismáticos, curados a 28 dias, com dimensões de 6,5 x 6,5 x $30 \mathrm{~cm}$ (figura 2), para cada traço a ser analisado. Iniciou-se com o traço 1:1, sendo um quilograma de cimento CPII, um quilograma de agregado miúdo e $400 \mathrm{~mL}$ de água pura para se obter um concreto de $40 \mathrm{MPa}$. O segundo traço a ser analisado foi 1:2,17, sendo um quilograma de cimento CPII, dois quilos e 170 gramas de agregado miúdo e $600 \mathrm{~mL}$ de água pura para se obter um concreto de $20 \mathrm{MPa}$.

Em sequência foram confeccionados os corpos

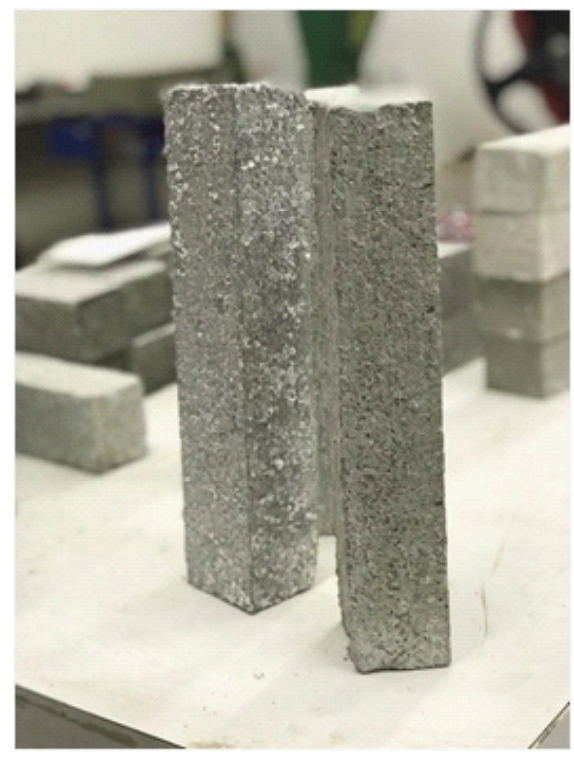

Figura 2. Corpo de prova prismático

Fonte: Autores (2019)

de provas com a fibra de polipropileno adicionadas em 20 gramas sobre a quantidade de cimento $(2 \%$ de teor de fibra) em cada traço, utilizando a mesma relação dos traços de concreto puro para obter um concreto de $20 \mathrm{MPa}$ e $40 \mathrm{MPa}$. A tabelalapresenta a proporção de cada componente empregado para a realização de cada traçode forma mais explícita.
Para a obtenção dos resultados, tal ensaio foi realizado em uma prensa a uma velocidade de $1,2 \mathrm{MPa} /$ min, de acordo com a norma ASTM C293-02-Standard Test Method for Flexural Strength of Concrete (Using Simple Beam With Center-Point Loading) que também indica que o espaço entre as extremidades do corpo de prova e ossuportes de cargasão de $2,5 \mathrm{~cm}$ ou mais, como

Tabela 1. Quantitativo dos componentes empregados em cada traço

\begin{tabular}{|c|c|c|c|c|}
\hline \multirow{2}{*}{ MATERIAIS } & \multicolumn{2}{|c}{ SEM FIBRA } & \multicolumn{2}{c|}{ COM FIBRA } \\
\hline CIMENTO & $20 \mathrm{MPA}$ & $40 \mathrm{MPA}$ & $20 \mathrm{MPA}$ & $40 \mathrm{MPA}$ \\
\hline AREIA & $1 \mathrm{Kg}$ & $1 \mathrm{Kg}$ & $1 \mathrm{Kg}$ & $1 \mathrm{Kg}$ \\
\hline ÁGUA & $2,17 \mathrm{Kg}$ & $1 \mathrm{Kg}$ & $2,17 \mathrm{Kg}$ & $1 \mathrm{Kg}$ \\
\hline FIBRA & $600 \mathrm{ml}$ & $400 \mathrm{ml}$ & $600 \mathrm{ml}$ & $400 \mathrm{ml}$ \\
\hline
\end{tabular}




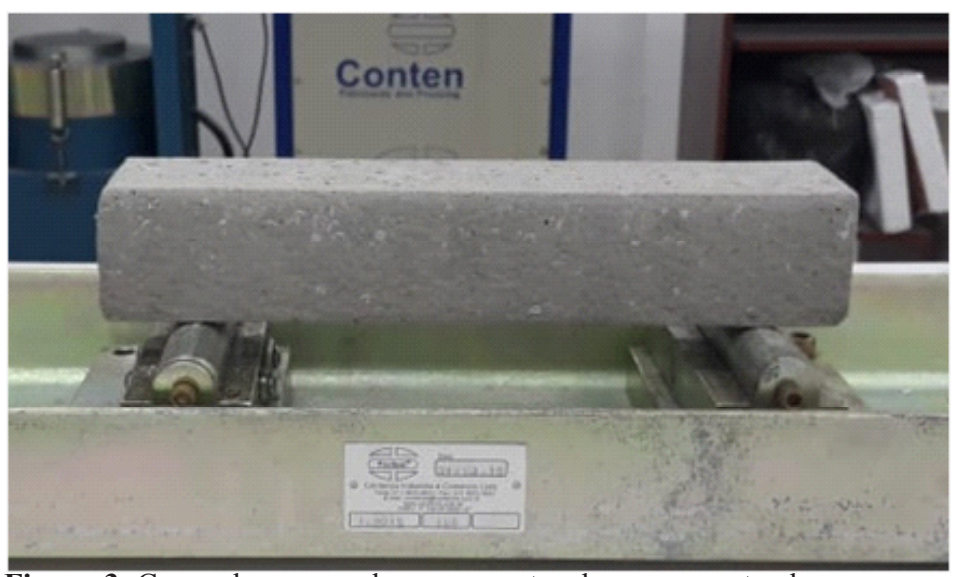

Figura 3. Corpo de prova sobre os suportes de carga mantendo o espaçamento conforme a norma ASTM C293-02

Fonte: Autores (2019)

mostrado na figura 3, onde foi usado o espaçamento de $2,5 \mathrm{~cm}$. Tal norma foi usada pois não existe uma norma brasileira para esse tipo de ensaio. Os valores apresentados correspondem à média para cada tipo de amostra.

\section{Resultados e discussões}

A partir do ensaio de flexão de três pontos, foram obtidos os resultados, dentre os quais são apresentadas as médias aritméticas do tempo de ruptura para cada tipo de amostra, conforme a tabela 2. Observa-se que o tempo que cada corpo de prova leva até chegar à ruptura, varia de acordo com o traço e adição ou não de fibra de polipropileno. É possível notar que as amostras com fibras, apresentam um maior tempo para chegar ao estado limite último, ou seja, estas amostras apresentam uma deformação maior, reduzindo seu comportamento frágil, logo aumentando a sua ductilidade, devido às pontes de transferência de tensões que as fibras formam nas regiões fissuradas. Tal comportamento, aumenta o patamar de escoamento do material, permitindo que o mesmo suporte valores deformações que em outro regime de escoamento (sem fibra) o levaria à fratura.

Os concretos reforçados com fibra respondem com uma melhora na resistência à fadiga, além de apresentarem melhor desempenho após a formação da primeira fissura (figura 4). Sobre a formação da primeira fissura, elas podem apresentar comportamento de acréscimo ou manutenção da carga, quando submetidos a esforços de tração, após a primeira fissura formada.

A adição de fibras permite controlar a formação defissuras secundárias, aumentando a tensão de tração e a energia de fratura e, portanto, evitando falhas frágeis após a ocorrência das fissuras iniciais. Após a formação da primeira fissura, o esforço de tração pode ser mantido ou acrescido para uma mesma deformação. Esta é a razão pela qual o concreto com fibra exibe um comportamento

Tabela 2. Tempo médio em segundos e em minutos, respectivamente, de ruptura dos corpos de prova.

\begin{tabular}{|c|c|c|c|}
\hline \multicolumn{2}{|c|}{ SEM FIBRA } & \multicolumn{2}{c|}{ COM FIBRA } \\
\hline 20 MPA & 40 MPA & 20 MPA & 40 MPA \\
\hline $22,2 \mathrm{~s}$ & $38,5 \mathrm{~s}$ & $2112 \mathrm{~s}$ & $2664 \mathrm{~s}$ \\
\hline $0,37 \mathrm{~min}$ & $0,64 \mathrm{~min}$ & $35,2 \mathrm{~min}$ & $44,4 \mathrm{~min}$ \\
\hline
\end{tabular}

altamente dúctil (Figura 5) em oposição ao concreto simples que é um material frágil. O fenômeno que dá origem a essa ductilidade é a inclusão de fibras curtas dispersas que funcionam como pontes entre superfícies fissuradas microscópicas na matriz de cimento.
Fazendo uma análise apenas observando traço por traço, tem-se, com $20 \mathrm{MPa}$ um tempo médio de ruptura de 22,2 segundos quando não há a adição de fibra em sua matriz enquanto, quando há a adição desta, o tempo médio é de 2.112 segundos para que o corpo 
venha a romper completamente, como mostra a figura 6. Assim, é possível atingir valores de deformação, que influenciam no comportamento mecânico do material.

O corpo com $20 \mathrm{MPa}$ com fibra apresentou um tempo de ruptura 55 vezes maior, aproximadamente, quando comparado ao corpo de $40 \mathrm{MPa}$ sem fibra, que apresentou um tempo médio de 38,5 segundos para romper.

Os compósitos com fibra quando acometidos a solicitações de tração indireta apresentam uma fase

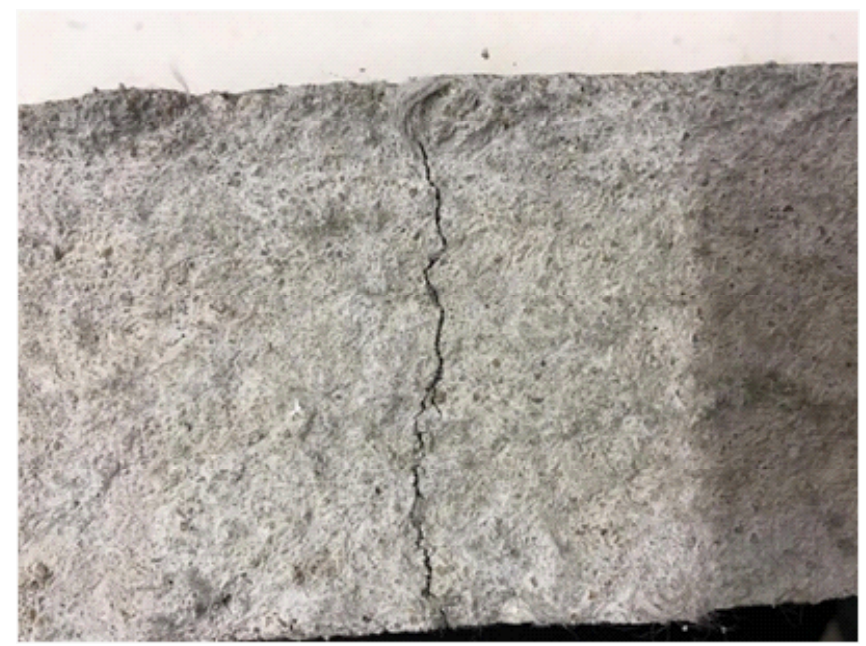

Figura 4.Corpos de prova em detalhe com fissuras em estágio inicial

Fonte: Autores (2019) linear elástica, até o aparecimento da fissura inicial. Após a fissuração da matriz, conservaram a eficiência portante, apontando um enrijecimentocom elevada capacidade de deformação e formação de múltiplas microfissuras as quais se comportam de maneira estável e controlada, enquanto novas fissuras vão aparecendo.

Devido a capacidade de deformação e domínio de abertura de fissuras na tração indireta, os compósitos podem ser empregados em situações diversas, onde a carga solicitante ocasiona uma deformação compulsória

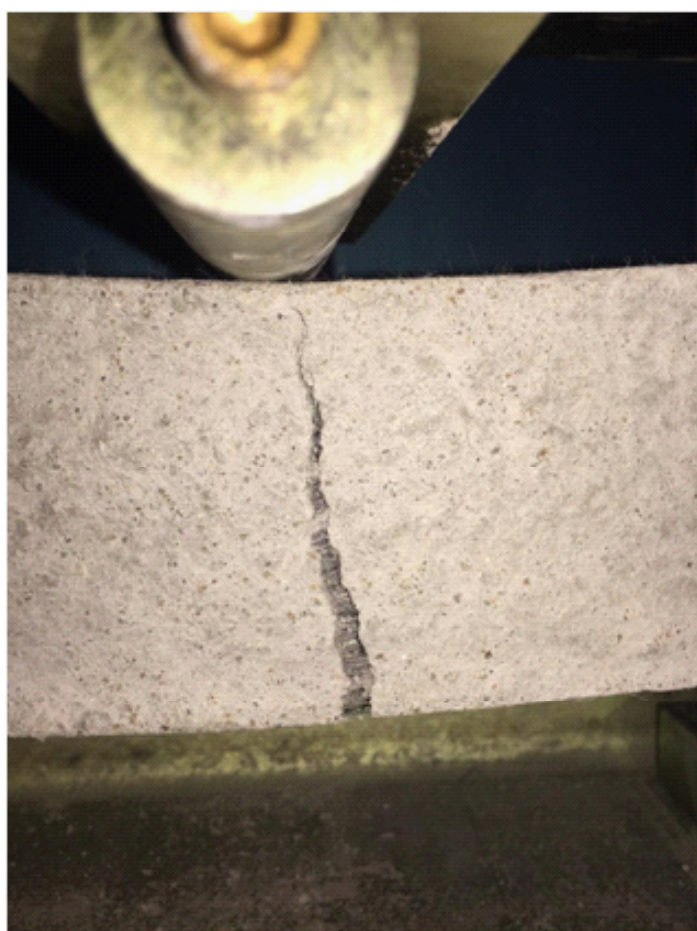

Figura 5. Matriz cimentícia rompida com as fibras agindo como ponte de transferência de tensões

Fonte: Autores (2019)

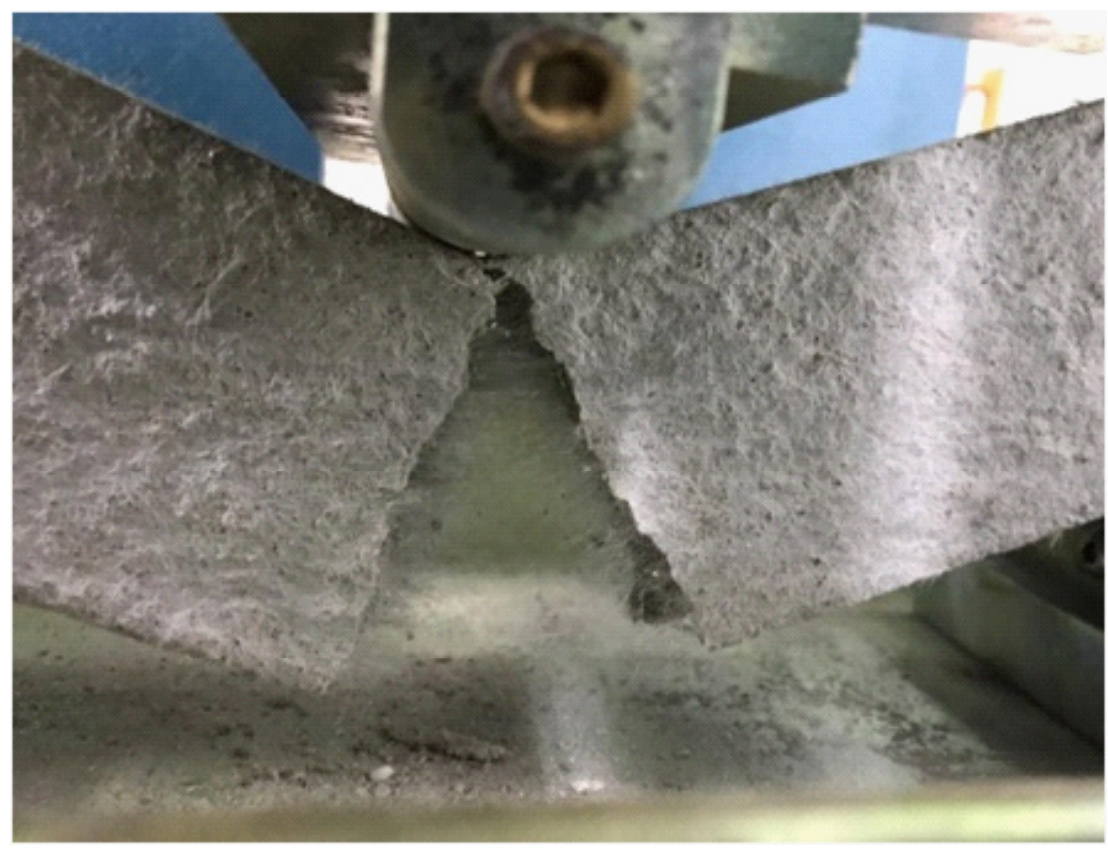

Figura 6. Rompimento total do corpo de prova

Fonte: Autores (2019) 
e, em elementos estruturais onde há restrições de fissuração, podendo ser utilizados como reparo e reforço de estruturas danificadas, uma vez que uma das principais característicasdeste tipo de compósito, é a de trabalhar muito bem, mesmo no estado fissurado.

\section{Conclusão}

Devido a este comportamento frágil, ao longo das últimas décadas há uma concentração de estudos objetivando desenvolver materiais cimentícios reforçados com fibras, com a finalidade de ampliar a capacidade de absorção de energia, garantindo às estruturas maior resistência a solicitações combinadas e tenacidade, além de promover um maior controle no processo de fissuração, impactando no aumento da durabilidade do material.

O concreto reforçado com fibrasse comporta sob solicitações de flexão como um material dúctil, com alta capacidade no desempenho em situações de deflexão, com elevada capacidade de se deformar, concomitante a abertura de finas fissuras, permitindo que o mesmo opere numa condição multifissurado. A ductilidade deste material provém da geração de microfissuras que se comportam de forma contida até que se atinja o limite de deformação do material. Estas propriedades garantem larga utilização em situações em que a carga atuante principal promove deformações.

Por fim, conclui-se que a adição de fibra em uma matriz cimentícia diminui a fragilidade que o corpo tem após o tempo de cura, fazendo com que sua ruptura total venha a ser retardada, ou seja, não ocorre a ruptura brusca e imediata após o aparecimento de fissuras, que é comum em corpos de concreto convencionais. Isso se dá através da capacidade que a fibra tem de suportar as tensões provenientes dos esforços exercidos na estrutura. Busca-se com isso, no futuro, que materiais como a fibra sejam empregados com maior frequência.

\section{Referências}

Associação Brasileirade Normas Técnicas. (2003). NBR 5738: Concreto Procedimento para moldagem e cura de corpos de prova.

Associação Brasileira de Normas Técnicas. NBR 6118: Projeto de execução de obras de concreto armado, revisada em 2014. São Paulo

ASTM C293-02. (2002) Standard Test Method for Flexural Strength of Concrete (Using Simple Beam With Center-Point Loading), American Society for Testing and Materials, West Conshohocken, PA.

Bentur, A., \& Mindess, S. (2006). Fibre reinforced cementitious composites. Crc Press.

Borges, L. A. C. (2016). Ensaio de compressão de corpo de prova com duplo corte em cunha na avaliação de concretos com baixos teores de fibra de aço (Doctoral dissertation, Universidade de São Paulo).

Caldas Branco, A. de A. Tabela de Traços Eng. Caldas Branco, 1974.

Caratin, R. L. (2014). Desenvolvimento de compósitos de matriz cimentícia com reforços contínuos de fibras de carbono e fibras de vidro (Doctoral dissertation, Universidade de São Paulo).

Denardi, A. (2016). Concreto têxtil: uma revisão bibliográfica sobre desenvolvimentos, aplicações e perspectivas de estudos e empregos no Brasil.

Figueiredo, A. D. D. (2011). Concreto reforçado com fibras (Doctoral dissertation, Universidade de São Paulo).

Isaia, G. C. (Ed.). (2007). Materiais de construção civil e princípios de ciências e engenharia de materiais. Ibracon.

Jiang, W., \& Roy, D. M. (1992). Mechanical Behaviour of Advanced Cementitious Materials. In Proceedings of the 9th International Congress on the Chemistry of Cement, New Delhi, India (pp. 23-28).

Medeiros, A. (2012). Estudo do comportamento à fadiga em compressão do concreto com fibras.

Mehta, P. K., \& Monteiro, P. J. M. (2008). Concreto: microestrutura, propriedades e materiais. Ibracon.

Moncada, J. E. C. M., Flor, L., Silva, V., \& Pacheco, J. (2019). Estudo da adição de argila expandida e EPS como agregados na elaboração de concreto leve. Revista Eletrônica TECCEN, 12(1), 02-07.

Neville, A. M. (2015). Propriedades do Concreto-5 ${ }^{\text {a }}$ Edição. Bookman Editora.

Picanço, M. de S.(2005). Compósitos cimentícios reforçados com fibras de caruá. Tese (Mestrado em Engenharia Civil) - Pontífica Universidade Católica do Rio de Janeiro, Rio de Janeiro.

Silva, R. D. P. (2006). Argamassas com adição de fibras de polipropilenoestudo do comportamento reológico e mecânico (Doctoral dissertation, Universidade de São Paulo).

Tanesi, J., \& Agopyan, V. (1997). Compósitos reforçados com fibras plásticas para construção civil. Encontro Tecnologia de Sistemas Plásticos na Construção Civil, II, 1997, São Paulo. EPSP. São Paulo.

Ventura, A. M. F. (2009). Os Compósitos e a sua aplicação na Reabilitação de Estruturas metálicas. Ciência \& Tecnologia dos Materiais, 21(3-4), 10 19 